\title{
artículos
}

\section{La Cenicienta en las artes plásticas y el cine}

Eva María Ramos Frendo

Universidad de Málaga

PALABRAS CLAVE: Iconografía/ Cine

\section{RESUMEN}

En este trabajo hemos querido ampliar estudios anteriores en los que analizábamos principalmente dos filmes, Rebeca y Jane Eyre, hallando en ambos unos prototipos femeninos que describiamos como Nuevas Cenicientas. En esta ocasión, hemos estudiado cómo este icono, la Cenicienta, ha sido recogido por la pintura, las ilustraciones de cuentos y el cine, partiendo de los cuentos originales de Perrault y los hermanos Grimm, para poder ver las aportaciones que realizan los artistas y la incidencia de los diversos estilos artísticos.

ABSTRACT

This work is the continuation of two previous studies in which we mainly analyzed films like Rebeca and Jane Eyre, where we found feminine archetypes called New Cinderella. Now, we have studied how this icon, Cinderella, appears in paintings, cartoons and in cinema, on the base of original fairy tales by Perrault and the Grimm Brothers', in order to elucidate the contributions made by artists and the implication of the different artistic styles.

La Cenicienta es un cuento de gran antigüedad cuyo origen hay que buscarlo en oriente, donde inicialmente se difunde a través de la tradición oral. Esta difusión de los cuento verbalmente se debía a que en un principio la gente no sabía leer ni escribir, por lo que era muy común la reunión de la familia alrededor del fuego, donde los padres o abuelos narraban estas historias ${ }^{1}$.

Claro signo de esta procedencia oriental lo podemos apreciar en el elogio del pequeño pie de Cenicienta, algo que se solía considerar como un signo de virtud y belleza por parte de los chinos, además de la aparición de un zapato realizado en materiales preciosos.

Su primera versión escrita se produce en el siglo IX en China² ${ }^{2}$ La llegada a

* RAMOS FRENDO, E.M.: "La Cenicienta en las artes plásticas y en el cine", Boletín de Arte ${ }^{\circ}{ }^{28}$ Departamento de Historia del Arte, Universidad de Málaga, 2007, págs. 403-424.

1 PHILIP, N.: El libro ilustrado de los Cuentos de Hadas, Barcelona, Omega, 2003.

2 BETTELHEIM, B.: Psicoanálisis de los Cuentos de Hadas, Barcelona, Crítica, 1992, pág. 331 
occidente tuvo lugar con la obra de Giambattista Basile, titula La Gatta Cenerentola, publicada en 1634. Pero, realmente, la popularización de este cuento se produce cuando el escritor francés Charles Perrault (1628-1703), iniciador de los cuentos de hadas, la publica en 1697. Una nueva versión tendrá lugar de mano de los escritores Jacob (1785-1863) y Wilhelm (1786-1859) Grimm, de nacionalidad alemana, quienes recogieron la historia de la Cenicienta entre sus Cuentos de niños y del hogar que publicaron entre 1812 y 1857 . Además, de estas dos, existen otras muchas más versiones que son mucho menos populares.

Mas hoy día si realmente se conoce la historia de la Cenicienta es, sin duda, a raíz de la versión cinematográfica que en 1950 realizó Walt Disney y que sigue el relato de Charles Perrault. Antes de la misma, la imagen de la Cenicienta sirvió de inspiración a algunos artistas para su obra y, sobre todo, dicho cuento contó con numerosas ediciones ilustradas en las que se pueden observar una gran variedad de estilos junto con diferentes variaciones en el aspecto de los personajes y en la ambientación de las escenas.

Igualmente, la Cenicienta ha sido una historia recreada por el teatro, la danza y la ópera. Dentro de la ópera ha contado con diversas versiones, siendo la más famosa la realizada por Rossini, que se estrenó el 25 de enero de 1817 en el Teatro Valle de Roma. En esta ocasión, el libreto, aunque parte del cuento de Perrault, posee algunas variaciones de la historia original motivadas por causas diversas. Por un lado, desaparece el personaje del hada, dado que la burguesía italiana estaba acostumbrada en la opera bufa a la carencia de toda magia. En lugar del hada aparecerá el filósofo Alidoro que aporta a la protagonista una serie de consejos sobre normas clásicas de pensamiento. Otro personaje que desaparece es la madrastra, sustituida por una figura masculina, dado que en las óperas no podían haber más de tres papeles femeninos y eran muchos más los cantantes masculinos disponibles.

La Cenicienta en la pintura.

La plasmación de este personaje dentro de la pintura no ha sido muy abundante, pero, no obstante, contamos con algunos ejemplos en los que Cenicienta ha sido el centro de atención de los artistas.

La más antigua de las obras pictóricas [1] se fecharía hacia finales del siglo XVIII y pertenece al pintor Jan Walraven, del que tan solo conocemos que nace en 1728. La obra, como nos indica el título "Little Cinderella", presenta a una Cenicienta en la niñez, rodeada de palomas, bajo la sombra de un árbol. Estos elementos nos indicarían que el cuento que ha servido de inspiración al artista sería el de los hermanos Grimm ${ }^{3}$, donde un avellano, plantado sobre la tumba de la madre de la niña, y los pájaros que en él se posan, en su mayoría palomas, tendrán un papel de gran 


\section{Q E articulos La Cenicienta en las Artes Plásticas y el cine}
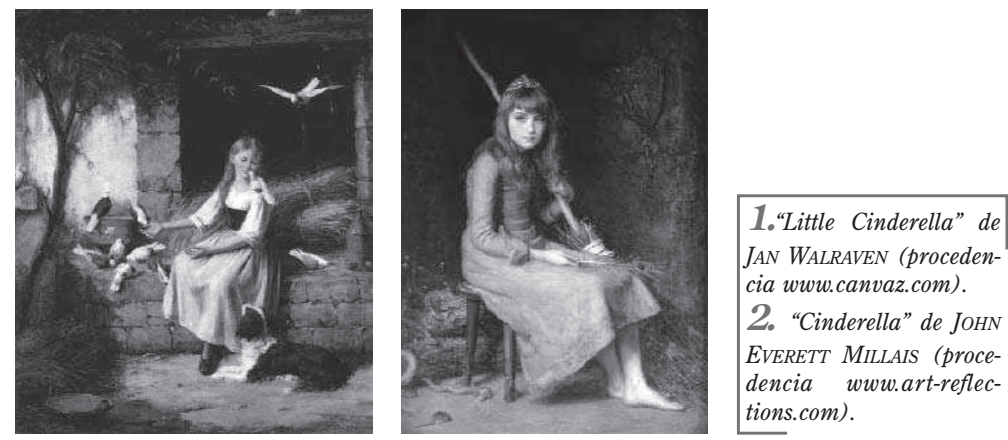

protagonismo en la historia, sustituyendo al hada de la versión de Perrault.

En el siglo XIX nos encontramos de nuevo con una joven "Cinderella" [2] realizada por uno de los fundadores del movimiento Prerrafaelista, John Everett Millais. El Prerrafaelismo fue un movimiento surgido en 1848 en Inglaterra que perseguía un estilo naturalista, siguiendo el modelo de los pintores del Renacimiento anteriores a Rafael, unido a una temática imaginativa y cargada de simbolismos y contenidos morales. Los más destacados iniciadores de esta hermandad fueron William Holman Hunt, Dante Gabriel Rossetti y Millais y se mantendrán unidos hasta el año 1856 en que cada uno seguirá un rumbo diferente. Millais, considerado un pintor de grandes dotes, optará por obras muy sentimentalistas y dulzonas que le proporcionaban un gran éxito ${ }^{4}$. Esas son las características que podemos apreciar en esta obra donde una Cenicienta aún en la niñez se dispone sentada, con la chimenea al fondo y los pies descalzos hacia los que se aproxima un pequeño ratón. Sostiene una escoba que nos indica su situación de sirvienta, mientras con una de las manos sostiene una pluma de pavo real que puede ser un símbolo que nos anuncia la posterior transformación que sufrirá cuando con los atavíos para la fiesta, deslumbre como el pavo real cuando abre su abanico de plumas.

Una nueva obra, fechada en 1863, es realizada por el pintor Edward BurneJones, considerado "el pintor más sobresaliente de los que se asocian a la segunda fase del prerrafaelismo" 5 . Burne-Jones, unido a lo largo de toda su vida al polifacético William Morris (diseñador, poeta, artesano, científico, hombre de negocios, ideólogo, etc.) será un gran admirador y amigo de uno de los fundadores del

3 Cfr. GRIMM, J. y W.: "La Cenicienta", en Cuentos de niños y del hogar, volumen I, Madrid, Anaya, 1985, págs. 152-161.

4 LUCIE-SMITH, E.: El Arte Simbolista, Barcelona, Destino, 1991, pág. 38.

5 Ibídem, pág. 44. 


2: artículos Eva María Ramos Frendo
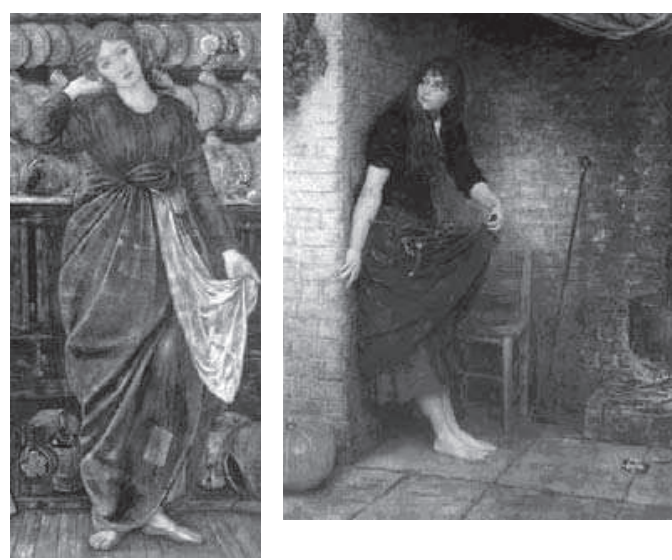

3. “Cinderella" (1863) de EDWARD BURNE-JONES (procedencia www.surlalunefairytales.com).

4. "Cinderella" (1899) de VAlentine Cameron PRINSEP (procedencia www.surlalunefairytales.com).

Prerrafaelismo, Dante Gabriel Rossetti, y seguidor de las ideas de John Ruskin, muy cercano en ciertos aspectos a los prerrafaelistas, quien consideraba al artista como una especie de sacerdote o profeta que, a través de la alegoría y el simbolismo de su obra, podía tener un importante papel moralizador en la sociedad, uniendo siempre sus temas imaginativos a un conocimiento detallado de la realidad objetiva 6 .

Burne-Jones será un enamorado de la Edad Media donde las obras de arte eran fruto de un proceso artesanal y rechaza la sociedad capitalista y el mundo industrial en que se desarrolla su vida. Por ello, su máximo deseo es crear obras bellas, razón por la que se le encuadra dentro de los denominados Esteticistas. Huyendo de su mundo busca la inspiración en los cuentos y leyendas, algo que se refleja en la obra que presentamos. Formalmente, sentirá una gran atracción por artistas como Leonardo, Miguel Angel, Mantegna y Botticelli.

Este contacto con los artistas italianos tiene lugar, por primera vez, en el año 1859, cuando Burne-Jones, animado por Ruskin y por otro destacado artista, George Frederick Watts (pintor muy influenciado por los venecianos), marcha a un viaje de seis semanas por diversas ciudades (Génova, Pisa, Siena, Padua, Venecia y Florencia). En esta última ciudad conocerá la obra de un artista que, formalmente, será decisivo en parte de su producción, Botticelli.

Esta influencia es totalmente clara en la obra "Cenicienta", realizada en 1863 , justo tras una segunda estancia en Italia que realiza en compañía de Ruskin en 1862.

6 CHRISTIAN, J.: “Los Prerrafaelistas”, en Simbolismo en Europa. Nestor en las Hespérides, Madrid, 1991, págs. $45-66$. 
En esta imagen podemos observar una clara copia de la pose de la Venus de Botticelli, a la vez que una gran similitud en esa cabeza con ligera inclinación y en el aspecto de su rostro. Tan sólo varía la disposición de los brazos, dado que uno de ellos, que en la Venus taparía la desnudes de sus senos, asciende para recoger la cabeza inclinada, y el colocado sobre el pubis se desplaza hacia un lado sosteniendo los ropajes. La joven se nos presenta en el interior doméstico, dispuesta ante un platero que expone una vajilla de gran lujo en color azul, presentando alguna de las características más frecuentes en Burne-Jones como es ese ensoñamiento que transmite la mirada perdida, unido a la ubicación del personaje en un espacio de quietud y silencio. La obra se nos presenta en un formato muy alto y estrecho, lo que también fue propio del artista. El momento recreado es el de la vuelta al hogar tras huir del palacio en el último baile, lo que podemos claramente apreciar en el pie descalzo que delata el objeto perdido, cuando ya los lujosos ropajes han desaparecido, volviendo a presentar los harapos que vestía en el domicilio paterno. Su cabellera aparece cuidadosamente recogida, algo que en esta época era claro indicio de la virtuosidad del personaje representado.

A finales del siglo XIX, concretamente en 1899, hallamos nuevamente la representación de Cenicienta [4] de la mano de Valentín Cameron Prinsep (18381904) que se nos ubica dentro del movimiento Prerrafaelista. Este artistas, más conocido como Val Prinsep, fue hijo de Sara Prinsep, hermana de la conocida fotógrafa Julia Margaret Cameron. El apellido Prinsep lo adoptó de su marido, Thoby Prinsep, miembro del Consejo de la India, y fue propietaria de Little Holland House, en Kensington, residencia en la que se reunían eminencias de la literatura, las artes y las ciencias. Dicha señora será la protectora del pintor Watts, quien a su vez tendrá al hijo de ésta como pupilo. Val Prinsep marchará en 1859 junto con Burne-Jones en ese primer viaje a Italia?

La obra de Prinsep nos presenta a una Cenicienta ubicada en el entorno que contribuyó a darle su nombre, esa chimenea con las cenizas a donde la joven, según Perrault, se retiraba a descansar una vez terminadas sus labores ${ }^{8}$. Cenicienta se nos presenta detenida, de pronto, de sus tareas, como nos indican la olla puesta al fuego y las verduras que recoge en sus faldas y mira hacia un lado de la habitación que los espectadores no podemos visualizar. Junto a Cenicienta podemos observar una gran calabaza, por lo que es posible que el momento plasmado sea justo el de la repentina aparición del hada madrina, justo antes de iniciar todos los preparativos para la marcha de la joven al baile.

7 Ibídem, págs. 58-59.

8 Cfr. "Cenicienta o el zapatito de cristal", PERRAULT, CH.: Historias o cuentos de antaño. Madrid, Anaya, 1987, pág. 139 . 


2: artículos Eva María Ramos Frendo
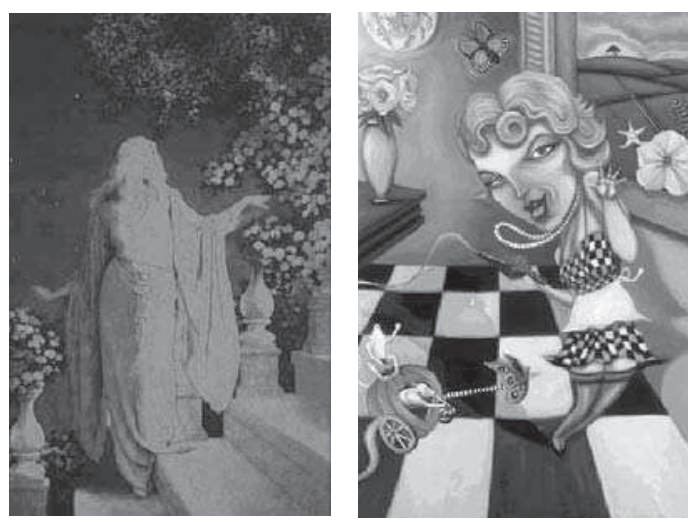

5. "Cinderella" (1913) de MAXFIELD PARRISH (procedencia www.surlalunefairytales.com).

6. Cinderella" de ADAM STONE (procedencia www.adamstone.com).

El pintor americano, Maxfield Parrish (1870-1966), nacido en Philadelphia, y destacado por su variada actividad (ilustrador de libros y calendarios, muralista, pintor de paisajes, etc.), también nos presenta en una de sus obras a la Cenicienta [5]. Según los críticos es un pintor con un estilo muy personal, no encuadrable en ninguna escuela. Sus obras mezclan la tradición junto con sus propias aportaciones, dando lugar a un estilo original, del que sobre todo se ha destacado su color, hablándose muy a menudo de los azules de Parrish. No obstante, la visión de algunas de sus obras denotan una clara influencia de los prerrafaelistas y simbolistas de fin de siglo.

En esta obra, realizada en 1913, nos muestra a una joven, en pose, apoyada sobre la balaustrada de una escalera, ataviada con un ropaje medieval, que únicamente nos muestra uno de sus pies que aparece calzado. El otro permanece oculto, quizás debido a la ausencia del zapato recién perdido. La Cenicienta se encuentra ante un paisaje nocturno, lo que nos indicaría que nos encontramos en uno de los bailes celebrados en el palacio. La presencia de la escalera y el protagonismo que tuvo en la perdida del preciado objeto que hace posible el triunfo de la protagonista es recogida en la obra de los hermanos Grimm, por lo que dicha versión debe haber sido la que sirve al pintor de referencia. Lo que no se consigue en esta obra es una adecuada ambientación, dado que el atavío medieval no concuerda con el estilo más barroco de la balaustrada. Casi da la sensación de ser una joven disfrazada para acudir a un determinado evento. Además, choca la quietud del personaje, cuando normalmente la Cenicienta en este espacio siempre nos va a ser mostrada en una actitud de huida.

La artista Svetlana Lopukhova nos presenta, en 1986, un obra titulada 
"Cenicienta, retrato de hermana", que podríamos encuadrar dentro del realismo mágico. La joven aparece envuelta en un ambiente irreal y misterioso, sin ningún elemento que nos pueda relacionar a la representada con el nombre que se ha elegido de título.

Más avanzado el siglo XX, encontramos una obra realizada por el americano Adam Stone, pintor nacido en Los Ángeles de California en 1966, que también se titula "Cenicienta" [6], algo que la misma pintura nos indica sobre todo por la presencia de dos ratones montados en una calabaza con ruedas que utilizan bastones de caramelo para atrapar mariposas. Cenicienta por su parte es una mujer moderna, con vestido a juego con las baldosas del suelo, que porta una especie de mini aspiradora y se halla en un interior doméstico hacia el que penetra una naturaleza amenazante. El espacio nos parece cómico a la vez que inquietante, sugiriéndonos un estilo muy cercano a la Nueva Objetividad que se desarrolló en la Alemania de los años 20 , plasmando imágenes muy veristas, que normalmente pretendían, con su perfecto acabado y sus obras detallistas, realizar una denuncia de la sociedad y el mundo en el que vivían. En este caso, el pintor parece simplemente haber querido plasmar un personaje de ficción de una manera muy peculiar. La escena se encuentra cargada de movimiento, sobre todo por parte de Cenicienta que se nos presenta en torsión y con postura inestable. Sorprenden los minúsculos pies que contrastan con el desmesurado tamaño de la cabeza.

\section{LAS ILUSTRACIONES PARA CUENTAS DE LA CENICIENTA.}

Frente a este escaso número de obras pictóricas, hallamos, como es lógico, gran número de imágenes que sirvieron para ilustrar las diversas ediciones del cuento de la "Cenicienta", bien fuera la edición de Perrault o la de los Hermanos Grimm.

Los libros ilustrados van a alcanzar un gran auge en el siglo XIX, consiguiendo sus imágenes una difusión inexistente en la pintura, dado que esta última es una imagen única e irrepetible. En el libro ilustrado, el dibujante se encuentra sometido al texto, debiendo plasmar en la imagen visual lo que el texto le está relatando. Además, no es un momento escogido el que recoge, lo que sí ocurría en la obra pictórica. Aquí, debe crear una serie de escenas con un orden ya establecido por la historia escrita.

Estas imágenes nos permiten seguir la historia y los elementos que las acompañan son un claro reflejo de la versión que están ilustrando. De este modo, una de las obras más antiguas ilustradas de la Cenicienta data de 1854 y el responsable de sus dibujos fue George Cruikshank (1792-1878), dibujante y caricaturista ingles, muy precoz, que influirá enormemente en Francia y España, sobre todo con sus ilustraciones de tipos y acontecimientos de la vida urbana. Además de caricaturas políti- 


- artículos Eva María Ramos Frendo


7. Cinderella and the Glass Slipper" en Fairy Library, London, 1854. Ilustración de GEORGE CRUIKSHANK (procedencia www.surlalunefairytales.com).

8. "Aschenputtle" en Grimm, Jacob y Wilhelm: Kinder und Hausmarchen, Munich, 1894. Ilustración de HERMANN VOGEL (procedencia www.surlalunefairytales.com).

cas y de costumbres, también tendrá una extensa labor como ilustrador de libros, entre ellos los cuentos. En 1823 ilustrará los cuentos de los hermanos Grimm, logrando unas escenas en las que demuestra su gran habilidad para plasmar elementos y entornos fantásticos y en la década de los treinta ilustrará las obras de Charles Dickens. Entre los años 1853 y 1864 realiza la obra Cruikshank Fairy Library, editada por David Bogue, apareciendo en el año 1854 el cuento de la Cenicienta. En esta época sus ilustraciones adquieren una gran libertad, sin buscar en ningún momento la verosimilitud, crea personajes fantásticos, como en este caso sería la hada que ayudará a Cenicienta9.

La imagen que sirve de portada al cuento [7] ya nos indica con claridad, a la vez que el mismo título que ilustra, que nos encontramos ante una versión del cuento de Perrault. Nos plasma a Cenicienta, acompañada de un hada que más bien nos recordaría a una pequeña gnomita. La joven se ubica en el que, según la historia de Perrault, era su lugar de descanso tras desempeñar las tareas diarias, el hogar de la casa, junto a la chimenea. Este espacio se nos muestra envuelto en un marco arqui-

9 BOZAL, V.: El siglo de los caricaturistas, Madrid, Historia 16, 1989, págs. 38-42. 
tectónico, dando la sensación que nos encontráramos ante un entramado teatral. La escena queda flanqueada por unas pilastras con burlescos mascarones. El basamento presenta, justo en su zona central, el zapato que tan determinante será para el desarrollo final de la historia. Sobre el entablamento, el cuerpo arquitectónico queda rematado por un frontispicio donde se colocan otros elementos fundamentales en la historia que ilustra.

De nuevo, centralizando el espacio se ubica el reloj, cuyas manecillas nos indican la cercanía de las doce de la noche, momento tan fundamental para Cenicienta en su asistencia al baile. Sobre él se dispone la calabaza que la Madrina transformará en carroza y la rata que ejercerá de cochero, además de mostrarnos dispersos los ratones-caballos y los lagartos-lacayos. Todo da lugar a una composición equilibrada y simétrica.

En todos los cuentos de la Cenicienta, como presentación del personaje, nos muestran ese entorno (el hogar con la chimenea cuyas cenizas manchaban a la joven) que le dio nombre y a la protagonista envuelta en harapos. Pero existen elementos que nos indicarán en que momento de la historia nos encontramos, como sucedía en la obra de Burne-Jones y también observamos en la ilustración que Warwick Goble nos presenta en 1913, es la presencia de la joven con un solo zapato y con sus harapos habituales, lo que nos ubica tras el último de los bailes, cuando la llegada de la medianoche ha hecho huir a la joven. Junto a la joven, la calabaza y una rata que muestran como el encantamiento ha desaparecido y todo ha vuelto a su estado habitual. Curiosamente, a la izquierda de la escena se puede apreciar la presencia de una rueca con un huso, lo que puede ser una cita a la otra famosa historia de la Bella Durmiente.

En 1894, el aleman Hermann Vogel [8] ilustrará el cuento realizado por los Hermanos Grimm. En este caso, nos aparece Cenicienta enfrascada en sus tareas junto a la chimenea, mientras las malvadas hermanas marchan lujosamente ataviadas hacia el baile, mirando de manera burlesca a la desdichada joven. La escena se completa con palomas que hacen alusión a los seres que ayudaran a Cenicienta a cumplir sus deseos. De nuevo el zapato centraliza la parte superior de la escena. Igualmente, Hellen Stratton [9], en 1903, nos ilustra con total claridad la versión de los hermanos Grimm, donde el hermoso vestido desciende portado por la paloma, desde el avellano plantado sobre la tumba de la madre. En otra edición anterior de los Cuentos de niños y del hogar, cuyo título original fue Kinder- und Hausmärchen y que se publicaría entre los años 1812 y 1857, la historia de la Cenicienta (Aschenputtel) será ilustrada por Theodor Hosemann (1807-1875), quien en este caso opta por mostrar el descendimiento de los zapatos, dado que debió considerar que tenían un papel mucho más definitivo en la historia. 




9. "Ascputtle" en Grimm, Jacob y Wilhelm: Grimm's Fairy Tales, London, 1903. Ilustración de HELLEN STRATTON (procedencia www.surlalunefairytales.com).

LIBERTAD DEL ARTISTA EN LAS ILUSTRACIONES.

No obstante, en las historias de Cenicienta, al igual que en otros muchos cuentos, existen ciertos elementos que no nos vienen descritos con claridad por el mismo. Por ejemplo, el personaje del hada, inexistente en la obra de los hermanos Grimm, sí aparece en el relato de Perrault, pero de ella no sabemos nada. El relato no especifica aspecto ni edad de la misma, algo que sí se nos aporta de Cenicienta de la que sabemos que era joven, dulce, bondadosa, hermosa, con buen gusto y que, debido a las circunstancias, vestía con malos vestidos. No obstante, hay datos, como el color del pelo, que no se especifican, por lo que nos encontramos con una Cenicienta que según el ilustrador puede ser rubia, morena o pelirroja, según los gustos.

\section{El Hada Madrina ${ }^{10}$}

De la Madrina sólo nos indica que era hada y nada más, por lo que a la hora de ilustrarla se han optado por muy diversas propuestas. Así, Cruikshank, como ya exponíamos, presenta un personaje de edad avanzada, lo que será lo habitual en la mayoría de los ilustradores, de diminuto tamaño, que nos recuerda a una pequeña gnomita, tocada con un sombrero cónico con ala redonda. Igualmente, Herbert Cole, en su edición de 1906, plasma a una anciana, con sombrero similar al anterior, pero

10 Cfr. "Las Hadas Madrinas" PHILLPOTTS, B.: El Mundo de las Hadas, Barcelona, Montena, 2003, págs. 82-83. 


\section{Q artículos La Cenicienta en las Artes Plásticas y el cine}


10. "Cinderella" en Racham, Arthur: The Arthur Rackham Fairy Book, Philadelphia, 1933. Ilustración de ARTHUR RACKHAM (procedencia www.surlalunefairytales.com).

11. "Cinderella" en Quiller-Couch, Sir Arthur, The Sleeping Beauty and Other Tales From the Old French, New York, 1910. Ilustración de EDMOND DULAC (procedencia www.surlalunefayritales.com).

de estatura normal, que se apoya en un bastón.

Por su parte, Arthur Rackham (1867-1939), dibujante y acuarelista inglés, ilustrará la Cenicienta en varias ediciones, partiendo en unos casos de la obra de los hermanos Grimm y en otras de la versión de Perrault. En 1933 [10] nos presenta un hada madrina que por su aspecto (manos con dedos largos y huesudos, gran nariz aguileña, vestuario negro y, de nuevo, con gorro cónico) nos acerca más a una bruja, por mucho que se intente en el rostro crear una imagen de bondad. Además, el ambiente de la escena, con fondos grises y negros y sombras que envuelven a los personajes, aún contribuye más a generar ese aspecto espectral y amenazante que rodea a la joven.

Otros ilustradores han seguido manteniendo esa imagen de hada madrina de edad avanzada, pero con un aspecto bondadoso, siendo en ciertos casos una figura elegante y esbelta, caso del hada de Millicent Sowerby (1915), mientras en otros se opta por una hada bastante entrada en carnes, como el hada de Margaret Evans Price de 1921. Los ropajes también varían haciendo que en ciertos casos el hada se nos acerque más a un ser ligado a los bosques y la naturaleza, los gnomos que antes mencionábamos, llevando una capa con capucha en forma de capirote, como 
ocurre con la figura de Margaret Tarrant de 1915.

Pero frente a esa opción mayoritaria de hada madrina de edad avanzada, el ilustrador Edmond Dulac, en su obra de 1910 [11], presenta una joven hada ataviada con un lujoso vestido que rivaliza en belleza con la protagonista.

Igualmente, Walter Crane (1845-1897), artista precoz, cuyos primeros encargos recibe a los 16 años de edad, y responsable de un cambio total en la concepción del libro ilustrado, donde se preocupa no sólo del dibujo, sino también del texto que pasa a incorporarse a la imagen, mostrará un hada inusual en su ilustración de 1875 [12]. Una figura alada, de rasgos muy botticellianos, que se presenta a la joven Cenicienta, que permanece sentada, creando una composición que ineludiblemente nos recuerda a las escenas de la Anunciación a la Virgen. Además, esta imagen nos permite ver las principales características del estilo de Crane. Por un lado, el predominio claro de la línea, delimitando las diferentes figuras, que se disponen en una escena donde no se intenta crear sensación de tridimensionalidad, al contrario las formas resultantes son muy planas generando siluetas más que volúmenes. Su obra se verá muy influenciada por los grabados japoneses que había estudiado, lo que se aprecia aun con mayor claridad en la escena que representa a Cenicienta en el baile. En dicha ilustración nos encontramos con un ambiente muy exótico y decorativo, donde prima lo ornamental por encima de la veracidad del espacio y, de nuevo, vemos ese gran protagonismo de la línea y un colorido totalmente plano ${ }^{11}$.

\section{CONTEXTO HISTÓRICO DEL CUENTO.}

Otro elemento que da total libertad al ilustrador es la ambientación histórica del cuento. Todos comienzan por "Erase una vez..." y no nos proporcionan ningún dato cronológico ni cita un lugar real donde aconteciera la historia, por lo que a la hora de ubicar los personajes en un escenario se debe optar por unos ropajes y un marco arquitectónico que serán los elementos que nos indiquen un periodo aproximado. Esto da lugar a múltiples opciones, como podemos apreciar en las diferentes ilustraciones.

De este modo, Cruikshank, en la escena final en la que se produce el enlace de Cenicienta y el príncipe, nos presenta el interior de una Catedral de estilo gótico. En escenas anteriores, la casa de Cenicienta presentaba vanos cuya parte superior terminaba en arcos ligeramente apuntados. Estos datos nos llevarían a una época medieval, pero el atuendo de las figuras masculinas, de difícil apreciación, y el aspecto de sus cabellos, con melenas no muy largas y con bigote y barba nos llevarían más bien al siglo XVI o comienzos del XVII. Además, en una de las escenas apreciamos

11 Ibídem, págs. 124-126. 

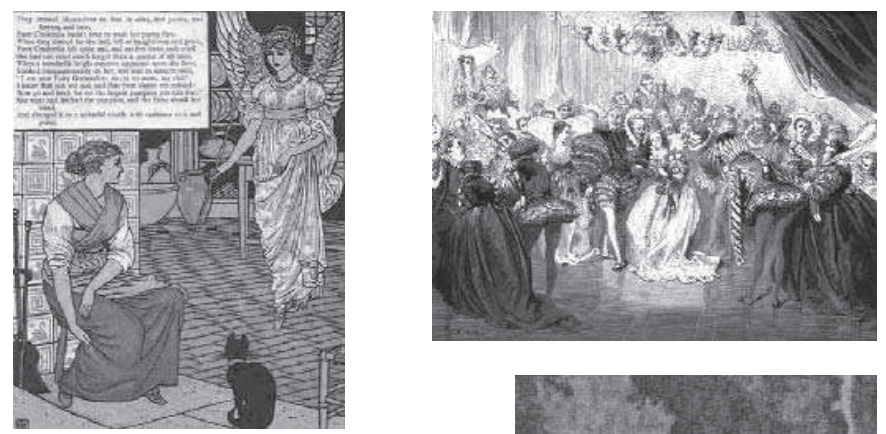

12. CRANE, WALTER, Cinderella, London, 1875 procedencia www.surlalunefayritales.com).

13. Les Contes de Perrault, dessins par Gustave DORÉ París, 1867 (procedencia www.surlalunefayritales.com).

14. "Cinderella" en Quiller-Couch, Sir Arthur, The Sleeping Beauty and Other Tales From the Old French, New York, 1910. Ilustración de EDMOND DULAC (procedencia www.surlalunefayritales.com).

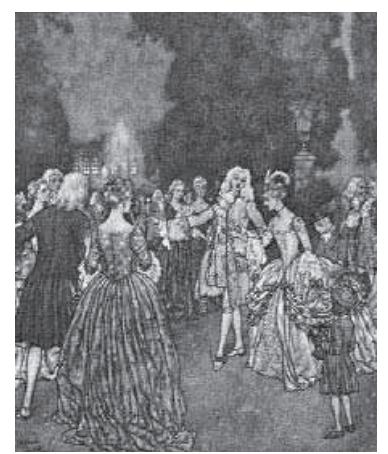

una construcción cupulada cuya estructura nos recuerda a las utilizadas en el Renacimiento, especialmente a la cubierta que Bramante proyectará para la basílica de San Pedro de Roma con cúpula sobre tambor con galería de columnas, lo que nos ubicaría de nuevo hacia el siglo XVI.

La escena que sí podemos encuadrar en un periodo medieval es la realizada en 1915 por Margaret Tarrant para ilustrar el libro Cuentos de Hadas, donde no existe marco arquitectónico, pero los atuendos de los personajes nos llevan claramente a dicho periodo. Cenicienta presenta un vestido de mangas muy anchas y entallado hasta las caderas, con falda cayendo hasta los pies y un generoso escote, que nos encuadraría hacia finales del siglo XIV, principios del XV.

El más importante ilustrador de la historia fue el francés Gustave Doré (1832$1882)^{12}$, con una carrera enormemente fecunda en la que se mostrará muy versátil, con caricaturas, escenas cotidianas, escenas costumbristas, ilustración de cuentos, etc., presentando estilos muy diversos. Entre sus ilustraciones destacar, por su relación con España, las que hizo en su obra Voyage en Espagne (1874) o las que

12 Ibídem, págs. 108-114. 
acompañaron a una edición de El Quijote de 1863.

En 1867 ilustrará los cuentos de Perrault, mostrándonos en el cuento de la Cenicienta [13] un barroquizante espacio en el que hombres y mujeres presentan recargados ropajes con unas exageradas gorgueras y mangas muy abultadas que nos ubicarían hacia finales del siglo XVI o comienzos de XVII ${ }^{13}$. Nos muestra una imagen paródica y con personajes muy caricaturescos. Los diversos gestos, exagerados igual que las vestimentas, y posturas nos plasman claramente el ambiente de cuchicheo y dinamismo que se produce ante la aparición de la joven Cenicienta, generando una escena muy retórica y teatral que nos resulta bastante humorística.

La ambientación más clara es la presentada por Edmund Dulac (1910) quien nos ubica en un escenario claramente versallesco [14], lo que podemos apreciar tanto por la arquitectura de grandes ventanales que nos recuerda a la realizada por el arquitecto Jules-Hardouin Mansart para Luis XIV, como por el gran protagonismo de los jardines en la escena que envuelven la residencia palaciega y presentan una naturaleza racionalizada, con fuentes y jarrones adornando estos últimos las balaustradas de manera similar a los que aparecían en los jardines diseñados por Le Nôtre. Igualmente los atuendos son claramente historicistas, sobre todo podemos apreciar aquellos elementos que se pondrán de moda en época de Luis XIV, como las casacas y chalecos largos que llegan hasta la rodilla o las corbatas (cravat) de encaje o muselina. Igualmente, es propio de finales del XVII y comienzos del XVIII el uso de las pelucas o postizos. En la ilustración podemos apreciar las denominadas pelucas in-folio que sería muy ostentosa y cara y presentaba una gran masa de rizos enmarcando la cara y cayendo por debajo de los hombros, convirtiéndose un elemento distintivo de las clases altas. Una época similar sería la que nos quiere plasmar Anne Anderson en su edición de 1935.

\section{INFLUENCIAS Y ESTILOS EN LAS ILUSTRACIONES.}

Los ilustradores reflejaron en sus creaciones la influencia de determinados estilos o artistas. Como ya mencionábamos en relación a la obra de Walter Crane es evidente el legado del grabado japonés. Del mismo modo, apreciábamos cierta influencia de Botticelli, que posiblemente le llegó a través de Burne-Jones de quien también en obras pictóricas deja patente su seguimiento ${ }^{14}$.Del mismo modo, BurneJones influirá en un dibujante e ilustrador ingles del fin de siglo, Aubrey Beardsley $(1872-1896)^{15}$, quien logrará un estilo muy personal, huye de la naturaleza y crea un

\footnotetext{
13 LAVER, J.: Breve historia del traje y la moda, Madrid, Cátedra, 1997.

14 LUCIE-SMITH, E.: El Arte Simbolista...Op. Cit., pág. 130

15 FERNÁNDEZ POLANCO, A.: Fin de siglo: Simbolismo y Art Nouveau, Madrid, Historia 16, 1989, págs.
} $69-73$ 
mundo artificial, donde desaparece cualquier referencia espacial y lo que predomina es la línea, en ocasiones configurando numerosos arabescos, y los contrastes de planos en blanco y negro. Uno de los temas más habituales en su obra, al igual que en el resto de los artistas simbolistas y decadentes del fin de siglo, será la femme fatale $^{16}$. Es una imagen de mujer muy erótica, perversa, y distante para el hombre, que ante ella adquiere un papel de sumisión total. Este icono es el resultado de la ruptura que hacen en el fin de siglo algunas mujeres con el modelo burgués femenino impuesto por la moral victoriana. El resultado es un icono femenino que siempre se muestra amenazante para el hombre.

Claras influencias de este dibujante podemos apreciar en el estilo que Arthur Rackham presenta en algunas de sus ilustraciones. Ha quedado constatado dicho influjo en las ilustraciones que realizó en 1910 para la ópera El oro del Rin de Wagner. Pero ya un año antes, en 1909, podemos apreciar similar estilo en la imagen que nos proporciona de la Cenicienta. Las líneas ondulantes del vestido, que parecen agitadas por el viento, nos vuelven a acercar al Art Nouveau, del mismo modo que la naturaleza que se sitúa coronando la escena. Cenicienta, por su parte, se nos muestra distante, como complacida por ese príncipe que queda indefenso ante sus encantos.

Sí Rackham sufrió la influencia de Beardsley, más clara aún se nos muestra la obra de Harry Clarke, de 1922 [15], donde podemos ver a Cenicienta convertida en una clara mujer fatal, con los pechos al descubierto y orgullosa ante el pobre sirviente que se agacha ante sus pies. Curiosamente el zapatito resulta minúsculo ante el gran tamaño de los pies de Cenicienta, por lo que la imagen nos lleva a pensar que la joven no podrá ser la agraciada. El espacio ha desaparecido, quedando sólo el mobiliario que nos indica la zona terrenal. En el fondo y flotando entre líneas ondulantes se nos plasma un personaje que debe tratarse del hada madrina. Del mismo modo, los arabescos, tan ligados al Art Nouveau, poblarán el exuberante vestido de Cenicienta.En otra de las escenas de la historia [16], Cenicienta aparece algo más ingenua, pero sin perder su erotismo al mantener la desnudes de sus senos a la vista, mientras un negro manto del príncipe acentúa los contrastes del negro y blanco.

También con influencia del modernismo tenemos la obra de A. H. Watson de 1927, donde podemos observar una escalera muy ondulante, cercana al estilo de Gaudí, con una moderna y estilizada Cenicienta, cuyo vestido presenta una pincelada muy suelta y abocetada. Dentro del mismo estilo se encuentra la Cenicienta que Alphonse Mucha, máximo exponente del cartelismo Art Nouveau, plasma en el anuncio de la obra teatral de Cenicienta, donde el cuerpo, vestuario y cabello de la joven se mueven generando múltiples curvas.

16 BORNAY, E.: Las hijas de Lilith, Madrid, Cátedra, 1995. 


Q E artículos Eva María Ramos Frendo
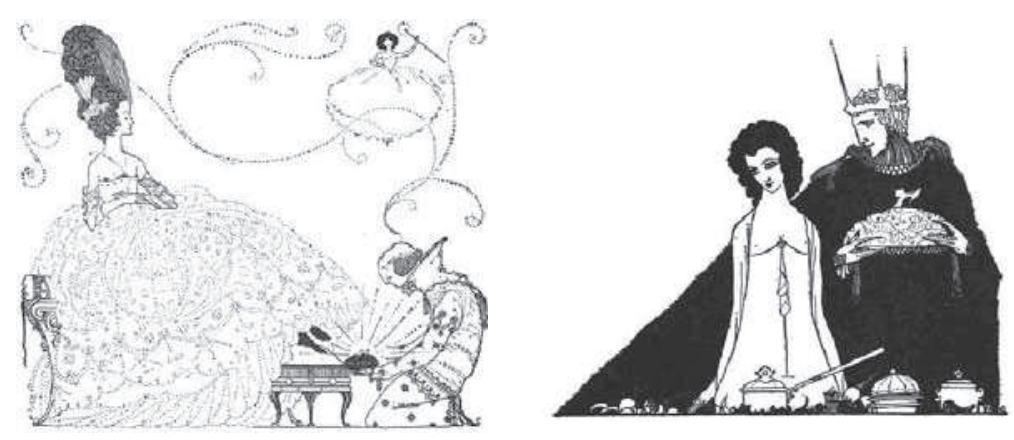

15. “Cinderella" en PERRAULT, CHARLES: Fairy Tales of Charles Perrault, London, 1922. Ilustrador HARRY CLARKE (procedencia www.surlalunefayritales.com).

16. "Cinderella" en PERRAULT, CHARLES: Fairy Tales of Charles Perrault, London, 1922. Ilustrador HARRY CLARKE (procedencia www.surlalunefayritales.com).

\section{la Cenicienta llega al cine.}

Pero la Cenicienta no sólo se difunde a través de la pintura y los cuentos ilustrados, sino que también será una historia llevada al cine. La más famosa de todas será la versión cinematográfica que Walt Disney realiza en 1950 partiendo de la obra de Perrault, nominada con un Oscar por su música y aclamada por la crítica.

Aunque antes de la versión de Disney existen algunas otras películas que retomaron el tema ${ }^{17}$. La más antigua será realizada en 1898 y fue una producción británica dirigida por George Albert Smith conocida como Cinderella o también Cinderella and the Fairy Godmother. Justo un año después, en 1899, contamos con un film francés dirigido por Giorge Méliès, quien en 1912 vuelve a retomarlo bajo el título Cendrillon ou La pantoufle mystérieuse.

En 1914, bajo la dirección de James Kirkwood, Mary Pickford protagonizaría otra versión en cine mudo del cuento. En 1922 se produjeron sendos cortos de animación de la historia, uno en Alemania y otro por parte de Walt Disney, en esta ocasión en blanco y negro. La animación en color de Cenicienta llegará en 1934 cuando, en la película Poor Cinderella, Betty Boop sea la intérprete de la desgraciada pro-

17 Para conocer más sobre las diferentes películas que recrean o versionan el cuento de la Cenicienta Cfr. www.surlalunefairytales.com. 
tagonista.Una versión modernizada del cuento se realizará en 1939 bajo el título First Love del director Henry Joster, protagonizada por la actriz Deanna Durbin.

Tras la versión de Disney de los años 50, llegarían otras muchas más, sobre todo en musicales realizados bien para la gran pantalla o para la televisión, junto con otras tantas películas de animación destinadas al público infantil. Dentro de los musicales citar el que bajo el título The Glass Slipper protagonizaría Leslie Caron, en 1955, bajo la dirección de Charles Walters. Tan sólo dos años después, Julie Andrews protagonizaría una nueva versión musical realizada para la televisión, que se volvería a producir en dos ocasiones más teniendo a Lesley Ann Warren, en 1964, y Whitney Houston, en 1997, como protagonistas respectivamente.

No obstante, en muchas más ocasiones la historia de la Cenicienta ha sido recuperada por la gran pantalla aunque con ciertas libertades a la hora de realizar las versiones del cuento. Este sería el caso de la película Por siempre jamás, estrenada en 1998, que protagonizaría Drew Barrymore, quien sufrirá las maldades de una madrastra encarnada por Anjelica Huston.

En otros casos se han realizado versiones modernas de la historia, convirtiéndose Cenicienta en una joven del siglo XX. Bajo el título Ashpet: An American Cinderella, en 1990, los americanos crean su propia Cenicienta, del mismo modo que en España sucedería con la película protagonizada por Marisol, con música de Augusto Alguero, para lucimiento de la artista. Incluso ha habido transposiciones iconoclastas de la historia como sucedería en 1960 con el Ceniciento de Jerry Lewis.

\section{El argumento cinematográfico de Cenicienta.}

Bajo el nombre de Cenicienta se han recogido numerosos argumentos cinematográficos ${ }^{18}$ que ya no son simplemente versiones más o menos modernizadas del cuento. A grandes rasgos esta denominación sirve para describir la historia de jóvenes que pasan por una serie de etapas, destacando una etapa inicial, más favorable, que se define como paraíso inicial, seguido de un posterior descenso, la pérdida, que lleva a la joven a pasar por toda una serie de penalidades hasta conseguir, finalmente, un nuevo ascenso social y el hallazgo del amor que serían los premios a unos comportamientos virtuosos, llegándose así a la felicidad final.

No obstante, en la actualidad muchas versiones modernas del cuento olvidan la primera de las etapas, el paraíso inicial, que sí quedaba totalmente expuesto en los cuentos originales. Tanto Perrault como los hermanos Grimm nos indican que la posición social de la joven Cenicienta era bastante acomodada antes de producirse

18 BALLÓ, J.; PÉREZ, X.: La semilla inmortal. Los argumentos universales en el cine, Barcelona, Anagrama, 1997, págs. 193-207 
los fatales acontecimientos del fallecimiento de la madre y el segundo enlace del padre con la malvada madrastras. Perrault claramente especifica que el padre de Cenicienta era un hombre rico y relata como tras la boda con la madrastra, ésta y las hermanastras fueron las responsables de que a la joven se le quitaran sus hermosos vestidos, poniéndosele en su lugar un delantal gris y unos zuecos. A partir de ese momento se la destina a la cocina expulsándola de los que habían sido hasta entonces sus aposentos ${ }^{19}$.

Por ello, aunque recogidas como modernas Cenicientas, tanto la película Pretty Woman producida en 1991 por Arnon Milchan y coproducida y dirigida por Garry Marshall, como la más reciente Sucedió en Manhattan (The Chambermaid) estrenada en la Navidad del 2002, olvidan en sus argumentos esa etapa inicial que sí se daba en el cuento e inician las historias partiendo de jóvenes que tienen una posición económica bastante dificultosa.

En el primer filme, la actualizada Cenicienta, protagonizada por Julia Roberts, sería una prostituta, mientras el príncipe, interpretado por Richard Gere, sería un ocupado hombre de negocios. Por su parte, en la versión más reciente, la Cenicienta, Jennifer López, es una madre soltera, puertorriqueña, que trabaja como criada en el Waldorf Astoria, mientras el príncipe, Ralph Fiennes, es un destacado hombre de negocios dedicado a la política.

Mas estos no son los últimos ejemplos, dado que en el año 2004 se han realizado nuevas versiones del cuento para el cine tituladas Ella Enchanted del director Tommy O'Haver, protagonizada por Anne Hathaway y A Cinderella Story de Mark Rosman, con Hilary Duff en el papel de Sam Montgomery, la Cenicienta de esta historia, y la magia de Internet para hacer posible el hallazgo del príncipe deseado.

Las protagonistas de Jane Eyre y Rebeca, dos nuevas Cenicientas.

Como ya expusimos en estudios anteriores ${ }^{20}$, en las películas Jane Eyre y Rebeca, hallamos argumentos que se adaptan perfectamente al designado como "Cenicienta". Según estos argumentos las protagonistas pasan por una serie de etapas: el paraíso inicial, la etapa de pérdida, la etapa de humillación y el triunfo final, que acaba con el castigo de los malos y la llegada del amor21.

Ambas películas poseen guiones adaptados a partir de novelas escritas por mujeres. La primera, Jane Eyre, fue una novela de la época victoriana, escrita por

19 Cenicienta o el zapatito de cristal", en PERRAULT, CH.: Historias...Op. Cit., pág. 152.

20 RAMOS FRENDO, E. M.: "Cenicientas actualizadas en las películas Alma Rebelde y Rebeca", Boletín de Arte $n^{\circ} 26$, Málaga, Departamento de Historia de Arte de la Universidad de Málaga, 2005. (en prensa )

21 BALLÓ, J. y PÉREZ, X.: La semilla inmortal...Op. Cit., págs. 195-196. 
Charlotte Bronttë en 1847. Mientras Rebeca nos llegaría de la mano de la escritora Daphne Du Maurier, quien la publica en 1938. Ambas relatan las historias de dos jóvenes cuyas vidas pasarán por similares circunstancias, aunque con varias décadas de diferencia.

Jane Eyre nos plasma a una joven de la época victoriana que tras perder a sus padres en la niñez (descenso de un paraíso inicial y comienzo de las penalidades, la etapa de humillación) será educada por una tía rica y malvada, la señora Reed, quien junto a su hijo maltratarán a la niña hasta que, finalmente, la llevan a un internado, Lowood, donde, con muchas penalidades, logrará formarse para ganarse la vida como institutriz, uno de los pocos trabajos que, en aquella época, se veían adecuados para aquellas jóvenes que, por necesidades económicas y carencia de familiares, no tuvieran más remedio que ganarse la vida ellas mismas. En la mansión de Thornfield ejercerá su labor educando a Adéle, joven protegida del dueño, Edward Rochester. Pronto surge la atracción entre Jane y Edward Rocherster, mas toda una serie de secretos se ciernen sobre el protagonista masculino dificultando la llegada del final feliz. Edward pedirá a Jane en matrimonio, pero, cuando el enlace se está realizando, se revela la cruda realidad, la presencia de una primera esposa, Bertha Mason, que padece una total demencia y permanece oculta en una de las torres de la mansión, lo que provocará la huida de Jane. Finalmente, Jane Eyre regresa a la mansión, tras haber escuchado la llamada telepática de su amado y se la encuentra en estado de total ruina, a causa de un incendio que ha sido provocado por Bertha Mason, la cual ha fallecido en el mismo (castigo de los malvados). Este hecho posibilitará el final feliz de la historia, el ascenso.

Esta novela será llevada al cine en varias ocasiones. La primera en 1934, bajo la dirección de Christy Cabanne. Más tarde, en 1944, Joan Fontaine protagoniza una nueva versión bajo el título Alma rebelde, dirigida por Robert Stevenson, donde el papel de Edward Rochester estaría a cargo de Orson Welles. Se han realizado nuevos filmes para la televisión y, en 1996, esta novela se llevaría otra vez a la gran pantalla por parte del director Franco Zeffirelly, con la actriz francesa Charlotte Gainsbourg para el papel de Jane y William Hurt como Edward Rochester.

En Rebeca la protagonista, que carece de nombre (tan sólo podemos conocerla como la nueva o segunda señora de Winter, dado que en ningún momento se la nombra en la historia), pasa por circunstancias similares a las acontecidas en Jane Eyre.

La película, primera dirigida por Alfred Hitchcock en América en el año 1940, está narrada en forma de flash-back. Nos relata la historia de una joven tímida y poco experimentada (Joan Fontaine), que tras quedar huérfana (de nuevo la caída tras una paraíso inicial, según el argumento de Cenicienta), se ve obligada a traba- 
jar como dama de compañía de una rica cotilla norteamericana, la señora Van Hopper. Durante una estancia en Montecarlo, conocerá a un viudo rico, Maxim de Winter (Laurence Olivier) con el que mantendrá una breve y extraña relación. Finalmente de Winter le pedirá a la joven que se case con él. La joven acepta y tras el enlace y luna de miel regresan a la mansión propiedad de Maxim, Manderley, una enorme y fantasmal residencia familiar situada en Cornualles.

Allí, la nueva señora de Winter será acogida con gran frialdad y desagrado por parte del ama de llaves, la señora Danvers (Judith Anderson), mujer de aspecto espectral que se encontraba muy unida (se habla incluso de enamoramiento) a la primera señora de Winter, Rebeca (se inicia así la etapa de humillación).

Poco a poco la recién llegada se va dando cuenta de que el recuerdo de la fallecida se encuentra aún presente en la casa y en la memoria de todos los que la conocieron. Esto la hará acumular un enorme complejo de inferioridad y sentirse fuera de lugar, incapaz de luchar contra el peso de un fantasma con el que todo el mundo la compara. Durante una fiesta de disfraces organizada para la presentación de la nueva esposa, se produce un naufragio que permitirá encontrar el cuerpo de Rebeca en el interior del yate sumergido y las sospechas recaerán sobre su esposo. Pero las investigaciones posteriores conducirán al descubrimiento de la verdad: la muerte de Rebeca había sido debida a un suicidio como consecuencia de su padecimiento de un cáncer avanzado e incurable. Al menos, esta es la verdad propagada, aunque la realidad fue que dicha muerte se debió a un accidente. Tras la aclaración de todos los secretos, el camino queda allanado para la futura felicidad de los protagonistas, quienes acabarán siendo testigos del incendio de Manderley fruto de un gesto de desesperación de la señora Danvers, quien acaba de conocer la noticia del suicidio de Rebeca y que morirá también entre las llamas que ella misma ha provocado (castigo de los malvados). Con esto finalmente se logrará el ascenso no logrado a lo largo de todo el filme.

De nuevo vemos totalmente justificado definir a la protagonista de esta novela y posterior película como una nueva Cenicienta. De hecho, en una entrevista realizada por el director francés Truffaut a Alfred Hischcock, este último afirmaba con referencia a la protagonista, la segunda esposa de Max de Winter, que era Cenicienta22

Del mismo modo, en la película, Jack Favell, amante de la difunta Rebeca, en su primera aparición en escena, se refiere a la protagonista como Cenicienta, nombre que no es utilizado, sin embargo, en la novela original 23 , lo que indicaría ese deseo de Hitchcock de realmente plasmarla como una nueva Cenicienta sufriendo,

22 TRUFFAUT, F.: El cine según Hitchcock, Madrid, Alianza, 1994, pág. 111.

23 DU MAURIER, D.: Rebeca, Barcelona, Orbis, 1987, págs. 124-127. 
en el que se supone que es su hogar, un continuo estado de inferioridad y sumisión, al no conseguir ocupar su papel de nueva esposa del dueño, debido a la continua presencia de la primera esposa.

Como podemos observar, en ambos casos, la pérdida de los familiares lleva a un descenso de posición social que obliga a las jóvenes a ganarse la vida por sí solas, una como institutriz y la otra como dama de compañía. Se produce así el descenso desde un paraíso inicial, para llegar a la segunda etapa definida como etapa pérdida.

Tras este cambio inicial, seguirá para ambas jóvenes el desarrollo de unas épocas de penalidades, la llamada etapa de humillación.

Jane Eyre se nos presenta como un ser inferior al señor Rochester, ejerciendo la función de institutriz. Ella misma es consciente de su papel de subordinada y, de este modo, le dice al señor Rochester: “- Yo jamás olvidaré lo que soy”. A su vez, la llegada de invitados a la mansión y el intento de ridiculizarla por parte de uno de ellos, la señorita Ingram (aspirante a cazar al señor Rochester y su fortuna), incide aún más en esta sensación de inferioridad que Jane Eyre experimenta. Dentro de esta etapa de penalidades se encontrará también el descubrimiento de la existencia de una primera esposa del señor Rocester, Bertha, que vive encerrada en una torre de la mansión, aquejada de una demencia total.

En Rebeca, aunque casi desde el inicio del film la protagonista ocupará un papel elevado al casarse con Max de Winter, convirtiéndose así en la señora de la mansión Manderley, sin embargo interiormente no asume esta recién estrenada posición social, dado que la presencia constante del recuerdo de la primera esposa y la actitud que hacia ella muestra la señora Danver, el ama de llaves, la llevan a no sentirse como la verdadera dueña de la casa. Incluso desde antes de llegar a su futuro hogar, la señora Van Hopper, para quien la protagonista trabajaba como dama de compañía, al conocer la noticia del futuro enlace, le dirá: - no te va el papel de señora de Manderley, sinceramente no creo que puedas desempeñarlo, no tienes experiencia, no tienes ni idea de lo que significa ser una gran señora. $Y$ en una escena posterior, en la que la protagonista rompe un candelabro chino del gabinete y decide esconder los trozos rotos por temor a que lo descubran, su esposo le comenta: - Te comportas más como una criada que como la dueña de la casa.

Además, durante todo el filme se multiplica la presencia de Rebeca 24 , no sólo por los comentarios continuos a su persona, sino, sobre todo, a través del atrezzo

24 Presencia y usurpación de protagonismo que ya se aprecia desde el mismo momento en que la novela y la película se titulan Rebeca. 
(libro de direcciones, pañuelos, servilletas, almohada, etc.) en el que hay una aparición de las iniciales o el nombre de la difunta. Además de esta presencia constante de Rebeca se encargará, principalmente, el ama de llaves, la señora Danvers, quien mantendrá las antiguas habitaciones de la difunta como si no hubiera pasado el tiempo y Rebeca pudiera volver en cualquier momento.

Visualmente la inferioridad a que es sometida la segunda esposa de Winter es dramatizada por medio de encuadres en plano medio que la presentan sentada ante la presencia en pie del ama de llaves quien la mira siempre de manera perversa, encuadres en picado o cuando la misma nos es mostrada en contraposición a la descomunal proporción de la mansión, que convierte a ésta última en un espacio negativo y hostil para la joven. Normalmente, la tensión que sufre la protagonista se acentúa al contrastarnos primeros planos de su rostro, con empleo de un foco selectivo que resalta esos primeros planos, contrapuestos a los del ama de llaves, origen de la turbación, momentos, éstos últimos, en que los espectadores nos identificamos totalmente con la protagonista, al adoptar su mismo punto de vista, por medio del uso de la cámara subjetiva. También son fundamentales todos los encuadres en plano medio corto que plasman las miradas enfrentadas de las dos mujeres, donde podemos observar el temor de la joven, frente a la mirada enloquecida del ama de llaves.

La situación de inferioridad de ambas protagonistas, como ya hemos expresado, finalizará cuando los malvados desaparezcan, llegando así la etapa de triunfo en que ambas logran la felicidad y el amor ansiado. Son, por tanto, sendas cenicientas.

Con todo esto podemos observar, como indicábamos en un principio, los diversos casos en que este personaje de cuento ha sido llevado a las artes plásticas, a las ilustraciones y al cine, aunque con diferencias en función de la fuente de la que tomen la historia y dependiendo también de los estilos artísticos en moda o de las aportaciones personales de cada uno de los creadores. 